\title{
TropPEAT Workshop on low-latitude peat-forming ecosystems
}

\author{
David W. Beilman', I. Lawson² and Z. Yu ${ }^{3}$
}

Honolulu, USA, 7-9 June 2017

Carbon in peat is one of Earth's single largest, organic, carbon pools. Recent improvements in estimates suggest that low-latitude, carbon-rich peatlands cover 387-657 thousand $\mathrm{km}^{2}$, hold more than 100 gigatonnes of sequestered carbon (Page et al. 2011; Dargie et al. 2017) concentrated in regional hotspots, and have been the largest component of natural wetland methane emissions globally since the pre-Industrial period (Paudel et al. 2016). Significant strides in research have been made recently (Dargie et al. 2017; Dommain et al. 2014; Sjorgersten et al. 2014), but peatlands globally, and tropical peatlands specifically, remain poorly understood compared to other terrestrial ecosystems.

The C-PEAT working group (see: http:// pastglobalchanges.org/ini/wg/peat-carbon), launched in 2014, identified several key subtopics related to global peat carbon including low-latitude peatlands. As part of C-PEAT's Phase 1, 20 experts and working group members came together in early June. Half of the participants were early-career or scientists from developing countries with expertise in understudied tropical regions. Our primary goals were to identify data and knowledge gaps in understanding low-latitude, peat-forming systems and to facilitate new collaborations and studies across geographies and career stages. From the many discussions at the meeting, two main research topics emerged.

\section{Where and how old are low-latitude, peat-forming ecosystems?}

A complete and accurate map of tropical peatland distribution remains elusive ( $\mathrm{Yu}$ et al. 2010) owing to limitations in data, methodology and logistics. As a near-term goal, key regions were identified where high-quality data exists or can be derived for low-latitude wetland distributions. With regional expert input from workshop participants, these are being compiled in a format to serve as validation data for Earth system model simulations (Kleinen et al. 2012).

\section{What are the controls on low-}

\section{latitude peat carbon formation?}

In contrast to cold, high-latitude soils with inherently limited microbial decomposition, tropical peatlands have different organic matter stabilization mechanisms with different vulnerabilities. Discussions of peat formation processes focused on the critical roles of topography (slopes, floodplains), hydroclimatic variability (orographic effects, fog inputs, monsoon climates), the rate and geography of human activities (logging, palm oil, traditional land use), and interac tions with other disturbances (flooding, fire) over timescales longer than polar peat carbon (through the Last Glacial Maximum and MIS3). A special issue publication is being planned as a venue for the discussed ideas and research conducted by participants.

A meeting took place at the AGU Fall 2017 Annual Meeting in New Orleans. C-PEAT Phase 2, currently in the planning and proposal stage, would continue activities in low-latitude peatland science.

\section{AFFILIATIONS}

'Department of Geography, University of Hawaii at Manoa, Honolulu, USA

${ }^{2} S c h o o l$ of Geography and Sustainable Development, University of St. Andrews, UK

${ }^{3}$ Earth and Environmental Sciences Lehigh University, Bethlehem, USA

\section{CONTACT}

Dave Beilman: beilman@hawaii.edu

REFERENCES

Dargie GC et al. (2017) Nature 542: 86-90

Dommain Ret al. (2014) Quat Sci Rev 97: 1-32

Kleinen T et al. (2012) Biogeosci 9: 235-248

Page SE et al. (2011) Glob Change Biol 17: 798-818

Paudel R et al. (2016) Env Res Lett 11: 034020

Sjorgersten S et al. (2014) Glob Biogeochem Cycles 28: 1371-1386

Yu Z et al. (2010) Geophys Res Lett 37: L13402

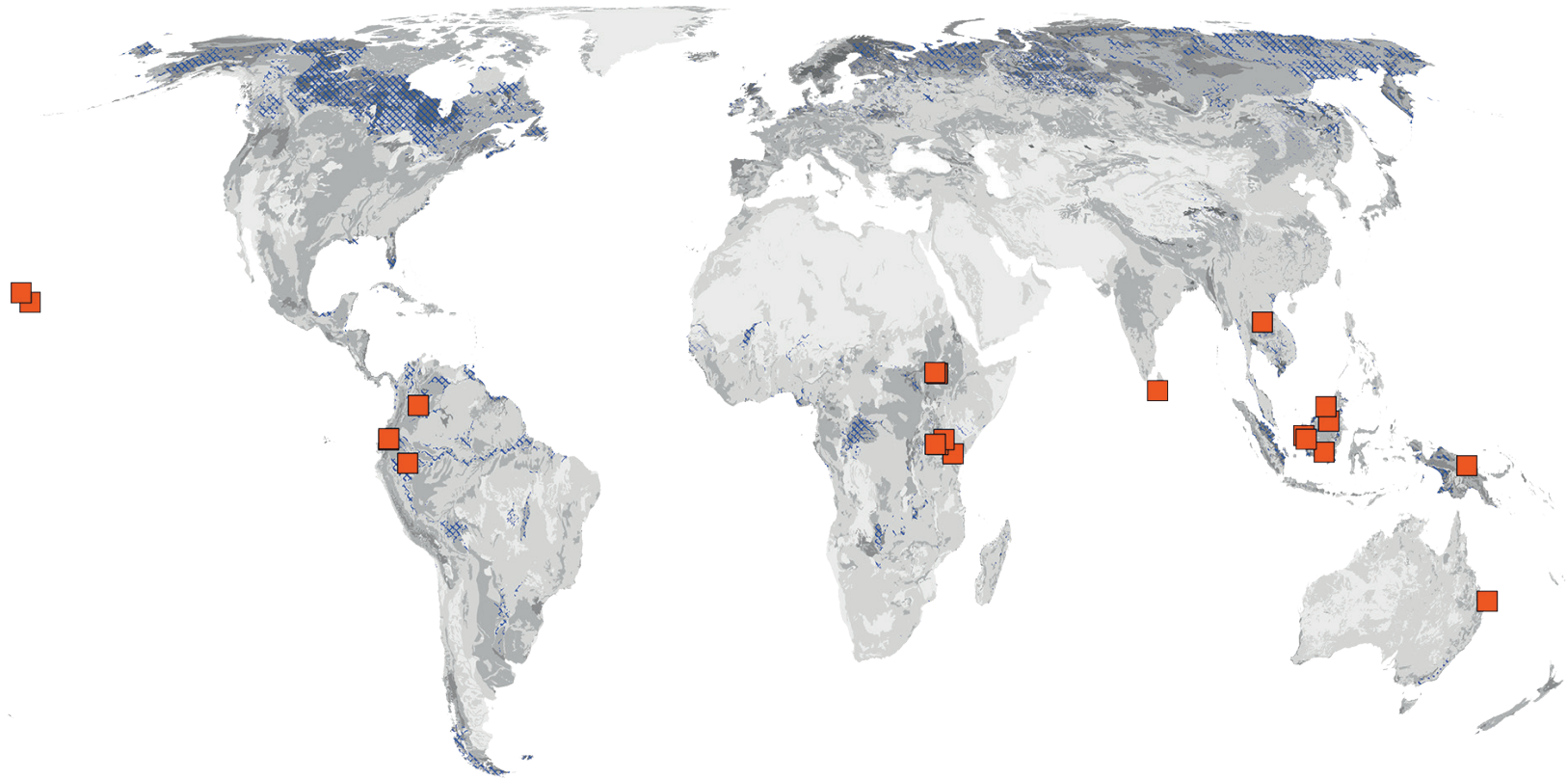

Figure 1: Location of study sites and regions with research results discussed at the TropPEAT workshop (red squares) along with peatland distributions in blue hatching (Yu et al. 2010) and global soil carbon density $\left(<5,6-10,11-20,21-40,>41 \mathrm{~kg} \mathrm{C} \mathrm{m}^{-2} ;\right.$ IGBP-DIS) in gray shades. 